\title{
Hydrotope-Based Protocol to Determine Average Soil Moisture Over Large Areas for Satellite Calibration and Validation With Results From an Observation Campaign in the Volta Basin, West Africa
}

\author{
Jan Friesen, Charles Rodgers, Philip G. Oguntunde, Jan M. H. Hendrickx, and Nick van de Giesen
}

\begin{abstract}
In West Africa, which is an extremely moisturelimited region, soil water information plays a vital role in hydrologic and meteorologic modeling for improved water resource planning and food security. Recent and upcoming satellite missions, such as SMOS and MetOp, hold promise for the regional observation of soil moisture. The resolution of the satellites is relatively coarse $\left(>100 \mathrm{~km}^{2}\right)$, which brings with it the need for large-scale soil moisture information for calibration and validation purposes. We put forward a soil moisture sampling protocol based on hydrotopes. Hydrotopes are defined as landscape units that show internally consistent hydrologic behavior. This hydrotope analysis helps in the following ways: 1) by ensuring statistically reliable validation via the reduction of the overall pixel variance and 2) by improving sampling schemes for ground truthing by reducing the chance of sampling bias. As a sample application, we present data from three locations with different moisture regimes within the Volta Basin during both dry and wet periods. Results show that different levels of reduction in the overall pixel variance of soil moisture are obtained, depending on the general moisture status. With respect to the distinction between the different hydrotope units, it is shown that under intermediate moisture conditions, the distinction between the different hydrotope units is highest, whereas extremely dry or wet conditions tend to have a homogenizing effect on the spatial soil moisture distribution. This paper confirms that well-defined hydrotope units yield an improvement at pixel-scale soil moisture averages that can easily be applied.
\end{abstract}

Index Terms-Geostatistics, hydrotopes, MetOP, satellites, scaling, soil moisture, Soil Moisture and Ocean Salinity (SMOS), West Africa.

Manuscript received February 28, 2007; revised November 5, 2007. This work was supported in part by the Global Change in the Hydrological Cycle (GLOWA) Volta Project, which is funded by the GLOWA program of the German Ministry of Education and Research (BMBF), and in part by the Ministry of Science and Research of North Rhine-Westphalia, Germany.

J. Friesen is with the Water Resources Section, Faculty of Civil Engineering and Geosciences, Delft University of Technology, 2628 CN Delft, The Netherlands (e-mail: j.c.friesen@tudelft.nl).

C. Rodgers was with the Center for Development Research, University of Bonn, 53115 Bonn, Germany. He is now a consultant, Washington, DC.

P. G. Oguntunde is with the Department of Agricultural Engineering, School of Engineering, Federal University of Technology, Akure 704, Nigeria.

J. M. H. Hendrickx is with the Department of Earth and Environmental Science, New Mexico Institute of Mining and Technology, Socorro, NM 87801 USA.

N. van de Giesen is with the Water Resources Section, Faculty of Civil Engineering and Geosciences, Delft University of Technology, 2628 CN Delft, The Netherlands.

Digital Object Identifier 10.1109/TGRS.2008.916638

\section{INTRODUCTION}

O ATELLITE-BASED soil moisture sensors, such as those $\checkmark$ onboard the European Space Agency's Soil Moisture and Ocean Salinity (SMOS) and EUMETSAT's MetOp satellites, require reliable spatial averages of soil moisture for calibration and validation. Recent advances in sensor technology and retrieval algorithms improve the satellites' capacity to measure soil water [1]-[3]. The spatial resolutions of these satellites range from 25 to $50 \mathrm{~km}$; therefore, ground observations have to cover large areas to provide pixel averages [4]. The presented hydrotope approach provides a methodology to obtain spatial averages during observation campaigns in data-scarce regions. The advantages of this method are a reduced uncertainty in the estimate of the average and a reduced risk of bias in the sampling scheme.

Different soil moisture ground-truthing methods are found in the literature. These were generally developed from a hydrological perspective, which is not specifically for satellite validation. The simplest methods for regions with limited station data and without data from observation campaigns use one or more observations in the close vicinity of the pixel [5]-[8]. Approaches that derive spatially representative soil moisture estimates from observation networks follow three main concepts, namely: 1) time-stability concept; 2) geostatistical approaches, such as kriging; and 3) landscape-unit approach.

Vachaud et al. [9] first introduced the time-stability concept. Point observations within a network or catchment are compared with a field average to identify locations that most accurately represent the field average without major under- or overestimations. The comparison is computed for each location and time step. Results are ranked by deviations from the field average and by temporal variability, identifying the most representative and temporally stable observation locations within a network. Several authors applied the modified time-stability concept by Kachanoski and de Jong [10]. Western et al. [11] applied this concept for network optimization in catchments in order to define observation points that best capture the catchment average. In terms of satellite pixel validation, the concept is applied to identify pixel-sized fields that show the least subpixel variability [12]-[14].

Kriging [15] has been widely used to interpolate field observations. The kriging concept is based on the assumption that the parameter to be interpolated continuously varies between two 
locations. Semivariograms are used to derive distance-based weights, and interpolated maps of ground observations are then used to validate satellite products (e.g., [16] and [17]). Both the time-stability concept and kriging were based on data from continuous observation sites such as the Tarrawarra study site [18] or the Global Soil Moisture Data Bank [19].

The third method is the landscape-unit approach, which is based on landscape-dependent processes that show internal consistency. In the context of hydrological modeling, Flügel [20] introduced hydrologic response units (HRUs) that are based on elevation, topographic sequence, soil type, slope, land use, and aspect. The different HRUs represent landscape units that show internally consistent hydrological behavior. Based on 23 different HRUs, Flügel built a hydrological model that represented most of the heterogeneity of the catchment. Park et al. [21] and Park and van de Giesen [22] applied a landscape-unit approach to the distribution of soils using a catena approach. Based on detailed topographic sequence data on a complex slope, nine landscape units successfully described the different soil-forming environments and the variability of the soils. Both studies successfully showed internally consistent hydrological behavior within their defined landscape units. The information used to define the landscape units required detailed spatial data, such as elevation, soil properties, and land cover, that are generally available at the observation site or subnational level.

The presented hydrotope methodology is a modified landscape-unit approach. It is meant as a statistical tool that assists in deriving representative field-average estimations on the basis of soil moisture sampling campaigns. Additional information required to identify and map hydrotopes involve local hydrological knowledge and globally available data sets.

The aim of this paper is to present a statistically stable methodology for satellite ground truthing through point measurements. Using a hydrotope-based sampling and analysis methodology, the overall footprint variance and the chance of sampling bias is reduced. The methodology is explained and proven by data from a case study in the Volta Basin, West Africa. However, it has to be made clear that the methodology as such is not limited to soil moisture sampling or locally to Western Africa but is, instead, generally applicable to any point-based sampling or data.

Section II describes the three West African study sites in detail. The methodology in terms of hydrotope identification, mapping, and hydrotope-unit separated averaging is outlined in Section III. Results are presented and analyzed in Section IV, and Section V concludes with the major results.

\section{STUdY Sites}

The study sites, which are Boudtenga, Tamale, and Ejura, are located in the Volta Basin, West Africa (see Fig. 1). The study sites are part of the Global Change in the Hydrological Cycle (GLOWA) Volta Project [23] that has been conducting field studies in the Volta Basin since 2001. The climate in this region is characterized by a clear seasonal pattern of wet and dry seasons [24]. Fig. 2 shows long-term rainfall and potential evaporation averages (1961-1990) for stations that are close to the study sites [25]. Rainfall, vegetation, and soil

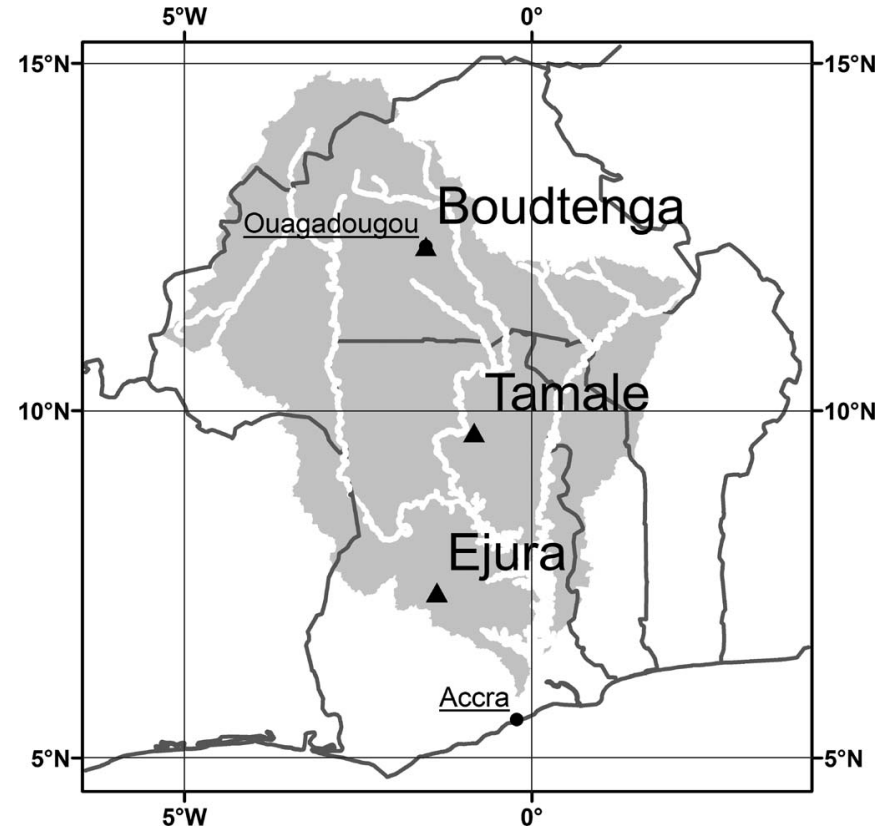

Fig. 1. Study site locations in the Volta Basin, West Africa.

moisture follow a gradient, which is with low rainfall in the north and high rainfall in the south. The study sites follow this gradient. Natural land cover at all study sites is interspersed with agricultural plots. Agriculture in West Africa is dominated by small plots well below one hectare. The size of the plots and mixing with natural vegetation lead to extremely high spatial heterogeneity. The annual seasonality and interannual variability of available water cause high temporal variabilities.

Boudtenga $\left(12^{\circ} 28^{\prime} \mathrm{N} / 1^{\circ} 15^{\prime} \mathrm{W}\right)$ is located in the northern part of the Volta Basin. The terrain is generally flat and interspersed with inselbergs (310-370 m). Landscape and vegetation are classified as Sudan savanna, and the agricultural vegetation is composed of maize, peanuts, sorghum, and millet. Trees include shea (Vitellaria paradoxa) and neem (Azadirachta indica). The mean annual rainfall from 1961 to 1990 is about $800 \mathrm{~mm}$. Rainfall follows a monomodal pattern, with a peak in August. The wet season lasts for roughly two months, which is from July until August, whereas the onset of the season shows high variability. The major soil in the Commission de Pédologie et de Cartographie des Sols taxonomy is "Sols ferrugineux tropicaux lessivés à tâches et à concrétions," which corresponds to Luvisols or ferric Lixisols in the taxonomy of the Food and Agriculture Organization of the United Nations.

The second study site, which is Tamale $\left(9^{\circ} 29^{\prime} \mathrm{N} / 0^{\circ} 55^{\prime} \mathrm{W}\right)$, lies in the central part of the Volta Basin in relatively flat terrain (160-240 m). Landscape and vegetation are classified as open woodland savanna, and the agricultural vegetation is composed of yams, maize, cassava, peanuts, sorghum, millet, rice, tomatoes, peppers, and onions. Trees include shea (Vitellaria paradoxa), mango (Magnifera indica), baobab (Adansonia digitata), neem (Azadirachta indica), dawadawa (Parkia biglobosa), and kapok (Ceiba pentandra). The mean annual rainfall over the 1961 to 1990 period is about $1100 \mathrm{~mm}$. Rainfall follows a monomodal pattern, with a peak in September. The wet season lasts for roughly four months, which is from July until October, whereas the onset of the season shows high 

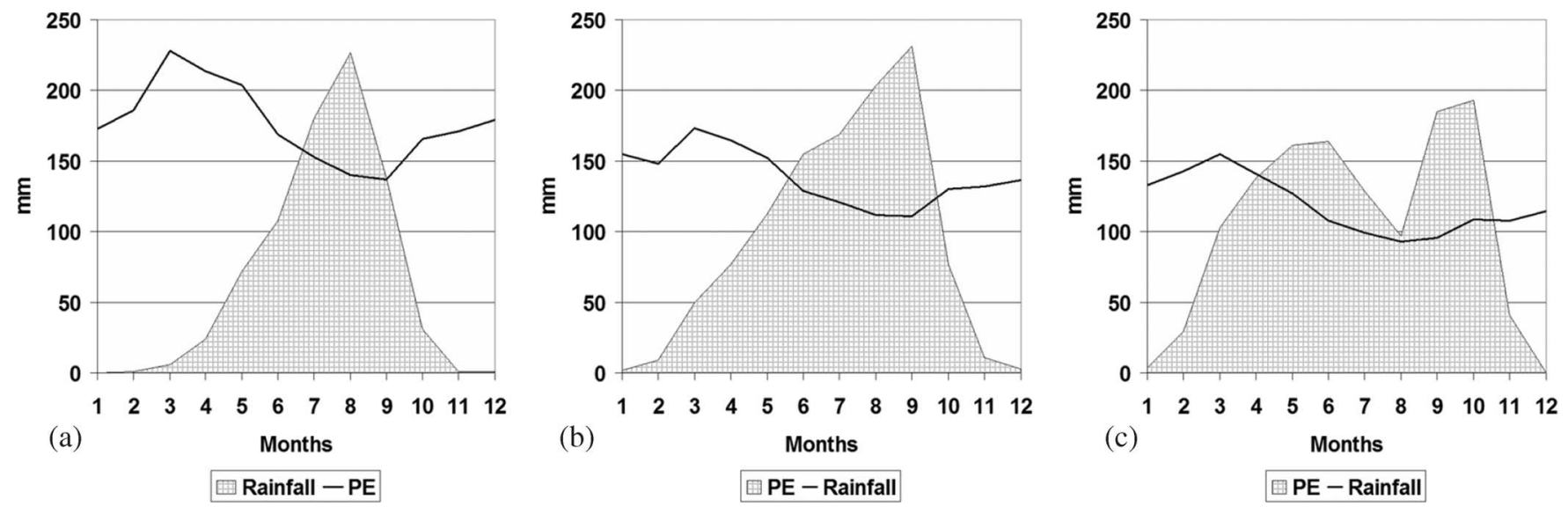

Fig. 2. Rainfall and potential evaporation (based on Penman) for climate stations close to the three study sites. Data from (a) Ouagadougou, BF (close to Boudtenga), (b) Tamale, GH, and (c) Wenchi, GH (close to Ejura). Source: FAOClim 2 [25].

variability. The major soils are Planosols and Acrisols over Alluvium and Voltaian sandstone. According to the Ghanaian soil taxonomy, the study site soils are Lima-Volta (Planosol) and Techiman-tampu (Acrisol).

The third study site, which is Ejura $\left(7^{\circ} 19^{\prime} \mathrm{N} / 1^{\circ} 16^{\prime} \mathrm{W}\right)$, is situated on the southern fringes of the Volta Basin in a slightly hilly terrain (150-250 m). It lies in the transition zone between forest savanna and mountainous guinea forest zone. The study site is located around a valley with vegetation covered with local food crops such as yams, corn, cassava; shrub, including elephant grass; and trees, among them cashew, various palm trees, and banana trees. The valley bottom is swampy, and the elevation differences are around $100 \mathrm{~m}$. The mean annual rainfall over the 1961 to 1990 period is about $1400 \mathrm{~mm}$. Rainfall follows a pseudo bimodal pattern, meaning that in August, it experiences a slight decrease and that the peak of the season is in September/October. The wet season lasts for roughly eight months, from March until October, whereas the onset of the season shows high variability. The major soils are Luvisols and Fluvisols over Alluvium and Voltaian sandstone. The Ghanaian soil taxonomy refers to these as Ejura-amantin/Ejura-denteso (Luvisol) and Damongo-techiman (Fluvisol).

\section{Methodology}

A hydrotope is defined here as a unit characterized by the dominance of similar hydrological processes. Hydrological variables, such as soil moisture, within clearly defined landscape or hydrotope units show reduced variability and consistent temporal patterns that distinguish the different units from each other. The basic concept of the hydrotope units is based on internally consistent hydrologic behavior within a certain landscape. Statistically, the chosen hydrotope units should show higher differences between the unit averages as compared with the variability within each unit. In the case of soil moisture, we can define the hydrotope units by means of the local hydrology. Hydrotopes are meant to improve the sampling schemes and the computation of field averages. This is done through the following: 1) reducing the number of required samples; 2) minimizing the sampling biases in the field average; and 3 ) reducing the overall variance.

\section{A. Sample Minimization}

Soil moisture sampling campaigns are meant to provide us with spatially representative field or pixel averages. Perfectly accurate moisture values would only be obtained if an infinite number of samples were taken. According to the central limit theorem, normality can be assumed for the overall sample means, which is given a sufficiently large number of samples

$$
\begin{aligned}
\bar{m} & \sim N\left(\mu, \frac{\sigma}{\sqrt{n}}\right) \\
N\left(\mu, \frac{\sigma}{\sqrt{n}}\right) & \approx N\left(\bar{m}, \frac{s}{\sqrt{n}}\right)
\end{aligned}
$$

where $\mu$ is the true mean value, $\sigma$ is the true standard deviation, $n$ is the number of samples, $\bar{m}$ is the mean value of the sample, and $s$ is the standard deviation of the sample. The parameters of the normal distribution can be estimated by $\bar{m}, s$, and $n$. The level of accuracy of the overall mean value therefore depends on the number of samples taken

$$
\bar{M} \sim \bar{m}+\frac{s}{\sqrt{n}} \times \bar{\chi}
$$

where $\bar{\chi}$ is the standard normally distributed variable. The average soil moisture and standard deviation can be based on either observed soil moisture data or on estimates. In the Volta Basin, a previous field study provided both the average and standard deviation. For a given confidence interval, one takes the corresponding minimum and maximum value of $\bar{\chi}$, such as $\bar{\chi}= \pm 1.96$ for a confidence level of $95 \%$. Now, solving (2) for $n$ using (1a) and (1b) allows us to derive the minimal number of samples needed to obtain an acceptable range for the average soil moisture value at a given confidence level.

\section{B. Hydrotope Mapping and Bias Minimization}

1) West African Hydrology: Soil moisture fields are determined by the local hydrology. To identify soil moisture hydrotopes, it is often helpful to use the knowledge of the local hydrological processes that are dominating within the region of interest. Based on the literature and on field work [24], [26]-[29] in West Africa, a schematized view of the 


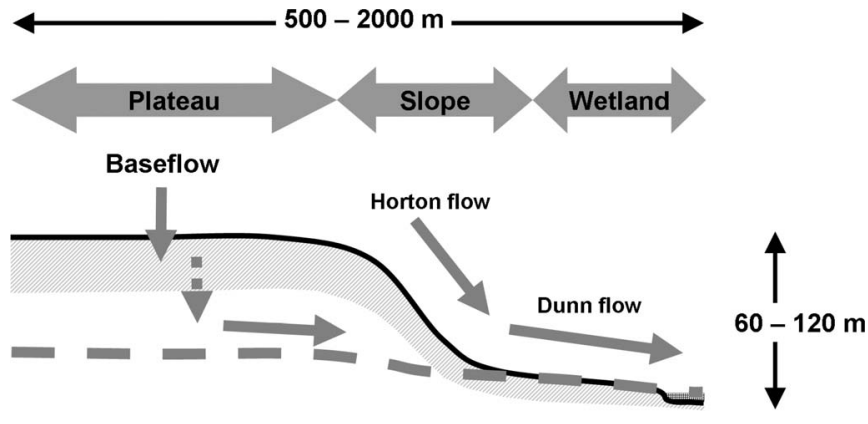

Fig. 3. Main runoff processes in the Volta Basin. The horizontal drain distance (500-2000 m) increases toward the north, considering that the distance between the streams becomes wider. The elevation difference $(60-120 \mathrm{~m})$ increases toward the south, where the relief is more pronounced (after Masiyandima et al. [27])

West African hydrology was built (see Fig. 3). From a hydrological point of view, it can be said that the landscape in the Volta Basin largely consists of inland valleys [24]. Within an inland valley, we can distinguish three main units [26], [27].

1) Plateaus are large upland areas, which are characterized by deep soils. Precipitation here is stored in the root zone, and this unit mainly contributes to runoff via subsurface flow.

2) Wetlands saturate very early during the wet season and contribute almost solely to the direct runoff or Dunn flow.

3) Slopes connect the plateaus to the wetlands. Both Hortonian surface runoff and shallow-groundwater flow occur on the slope unit. The hydrological state of the slopes tends to vary relatively quickly over time and space.

Topography defines, to a large extent, these three hydrotopes. Plateaus and wetlands are flat, and slopes have higher gradients. Plateaus have a small upstream area, whereas slopes and wetlands have larger upstream areas. Absolute height differences between plateau and wetland units do not enter into the hydrotope-unit delineation. The topography also defines the stream network; however, considering that the streams in our region of interest are ephemeral, not every stream is bordered by wetlands. Because of this, dry-season land cover is used to distinguish between the green wetlands and the surrounding bare slopes and plateaus.

The hydrotope-unit definition, as outlined in this paper, is very specific for the study region. Different climates and hydrologies require individual hydrotope-unit definitions that might also result in differing mapping strategies. The hydrotope-unit mapping that is described in the following was specifically done toward the described hydrotope-unit definition stated in this paper.

2) Remote Sensing Data Mapping: In order to incorporate the local hydrological knowledge into sampling schemes, the three identified hydrotope units have to be mapped regionally. For the three study sites, $10 \times 10 \mathrm{~km}$ windows have been selected to be mapped. Fig. 4 shows a sample hydrotope map for the Ejura study site. Globally available satellite data of Shuttle Radar Topography Mission (SRTM) elevation (http://srtm.usgs.gov) and land cover (such as Landsat, MODIS,

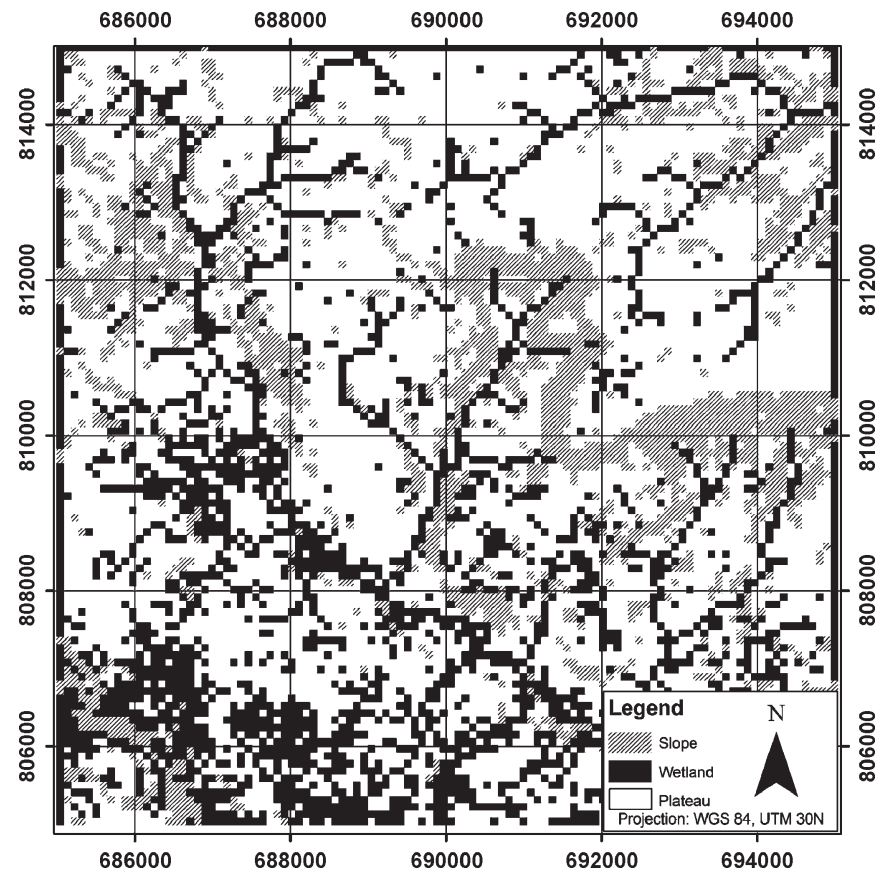

Fig. 4. Hydrotope map of the Ejura study site.

or Spot) can be used to regionally map the hydrotope units. The use of global data sets is particularly useful in data-scarce environments such as West Africa. A first step toward delineating the hydrotope units is to build slope, upstream area, and land cover maps. The choice of satellite data to be used strongly depends on the initial hydrotope-unit definition. The following data sources, classifications, and thresholds, therefore, only apply for the study region presented in this paper.

Slope and upstream area (using digital elevation model): Slope and upstream area maps are computed on the basis of the SRTM data. The SRTM data used in this study have a 90-m horizontal and nominal vertical resolution of $16 \mathrm{~m}$ (absolute) and $10 \mathrm{~m}$ (relative). Comparisons with kinematic GPS readings, however, show that over Africa, for $90 \%$ of the data, the absolute vertical error is estimated at $6 \mathrm{~m}$ [30]. Based on our comparisons between SRTM and detailed topographic maps, we postulate that the relative error between adjacent pixels is less than $2 \mathrm{~m}$ at the study sites. It should be stressed that for the presented hydrotope delineation, only the slope and upstream areas are used [see Fig. 5(a) and (b)], which are based on relative height differences. Slope maps are classified in slope and flat categories. The threshold between the slope and flat depends on the local relief. For our study sites, we chose a slope angle threshold of $2 \%$. This will mainly be used to distinguish between plateau and slope areas.

Land cover (using normalized difference vegetation index $(N D V I))$ : Land cover information from Landsat NDVI data was used to delineate wetlands. The Volta Basin experiences extremely dry and wet seasons (see Section II). During the dry season, vegetation is mostly limited to forest patches that are generally located in the wetland areas as gallery forests. Landsat NDVI images from the dry season were used to delineate the wetlands by using an NDVI threshold value. The vegetation immensely varies between the three study sites. An 

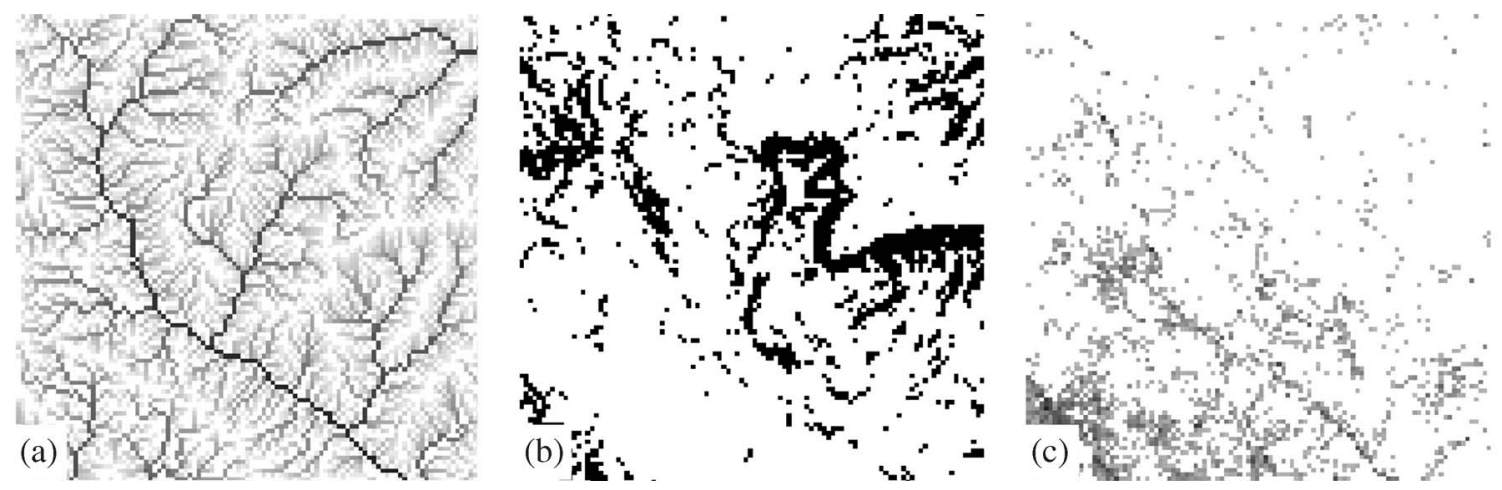

Fig. 5. Maps of (a) upstream area, (b) slope, and (c) NDVI for the Ejura study-site window (10 $\times 10 \mathrm{~km})$. For the slope, a threshold of $2 \%$ has been applied, and for NDVI, a threshold of 0.049 has been applied.

TABLE I

INDIVIDUAL THRESHOLD AND RANGE VALUES

\begin{tabular}{|c|c|c|c|c|c|c|}
\hline \multirow[b]{2}{*}{ Study site } & \multicolumn{2}{|c|}{ Upstream area $^{\mathrm{a}}$} & \multicolumn{2}{|c|}{ Slope ${ }^{b}$} & \multicolumn{2}{|c|}{$\mathrm{NDVI}^{\mathrm{c}}$} \\
\hline & Range & Threshold & Range & Threshold & Range & Threshold \\
\hline Boudtenga & 8.99 to 17.12 & n.a. & 0 to 17.21 & 2 & -0.214 to 0.370 & $>0.148$ \\
\hline Tamale & 8.99 to 16.90 & n.a. & 0 to 10.27 & 2 & -0.319 to 0.273 & $>0.049$ \\
\hline Ejura & 8.99 to 17.91 & n.a. & 0 to 15.63 & 2 & -0.260 to 0.213 & $>-0.030$ \\
\hline
\end{tabular}

Indivitual threshold and range values of the different input maps for all three study sites. On upstream area maps no threshold was applied. n.a. stands for not applied

${ }^{\mathrm{a}}$ Upstream area units are $\ln \left(\mathrm{m}^{2}\right)$; ${ }^{\mathrm{a}}$ Slope units are in percent; ${ }^{\mathrm{a}} \mathrm{NDVI}$ units are dimensionless

individual NDVI threshold for each of the three study sites had to be chosen to distinguish between wetland and non wetland areas.

Combination of maps: To combine the upstream area, slope, and land cover data into hydrotope units, the three data maps [see Fig. 5(a)-(c)] were used as input for an unsupervised classification [31] using the IDRISI CLUSTER function [32]. The IDRISI CLUSTER is based on a histogram peak selection technique. The slope and NDVI were filtered before entering the classification using thresholds, considering that the raw input maps show little distinction between slope and nonslope or wetland and nonwetland vegetation. Detailed information about thresholds and ranges are shown in Table I. The upstream area shows a clear distinction in values between main riverbeds and tributaries in our study region so that there was no need to filter the raw map data. A sample outcome is shown in Fig. 4, which shows the hydrotope distribution for the Ejura study site.

The hydrotope mapping shown in this part is only valid for the presented study sites. In different regions, the mapping process has to be modified. Modifications are then to be made in the data selection, map preparation, and classification or combination of the different data.

3) Bias Minimization: The hydrotope maps provide the total area for each hydrotope unit. Based on these areas, the total number of samples, as based on (2), was distributed over the hydrotopes (see Table II). Combined with the hydrotope maps, the number of samples taken for each hydrotope unit can be calculated by an area-weighed distribution of the total number of samples. This reduces the chance of bias in the field average caused by the over- or undersampling of individual hydrotope units. In this paper, data collection followed a hydrotope analysis to optimize the sampling procedure.
TABLE II

NUMBER OF SAMPLES

\begin{tabular}{lcccccc}
\hline \hline & \multicolumn{2}{c}{ Boudtenga } & \multicolumn{2}{c}{ Tamale } & \multicolumn{2}{c}{ Ejura } \\
& I & II & I & II & I & II \\
\hline Plateau & 155 & n.a. & 114 & 131 & 114 & 114 \\
Wetland & 42 & n.a. & 65 & 59 & 52 & 48 \\
Slope & 0 & n.a. & 8 & 14 & 34 & 38 \\
Total & 197 & n.a. & 187 & 204 & 200 & 200
\end{tabular}

Number of samples per hydrotope unit, study site, and sampling campaign. Partitioning of samples between campaign I and II may differ slightly as some samples were lost during the drying process. This is taken into account in the analysis of samples. n.a. stands for not applied.

\section{Hydrotope-Based Field-Average and Variance Computation}

Hydrotope analysis can be applied in advance to develop a hydrotope-based sampling scheme or a sampling scheme that is based on an existing soil moisture database. In terms of computation, this results in two options, namely: an areaweighed approach, where the hydrotope-unit areas are included in the computation of average and overall variance, and a hydrotope sampling approach, where the sampling is already area weighed and only the overall variance is to be reduced.

In terms of an area-weighed approach, the mean soil moisture and the standard deviation are first computed for each hydrotope

$$
\begin{aligned}
\bar{m}_{j} & =\frac{1}{n_{j}} \sum_{i=1}^{n_{j}} m_{i} \\
s_{j} & =\sqrt{\frac{\sum_{i=1}^{n_{j}}\left(m_{i}-\bar{m}_{j}\right)^{2}}{n_{j}-1}}
\end{aligned}
$$


where $n_{j}$ is the number of samples within hydrotope $j$ and $m_{i}$ represents the individual soil moisture samples within hydrotope $j$. The second step then computes both area-weighed mean soil moisture and the overall variance

$$
\begin{aligned}
\bar{m}_{w} & =\frac{\sum_{i=1}^{n_{j}} A_{j} \cdot \bar{m}_{j}}{A} \\
& =\frac{A_{1} \cdot \bar{m}_{1}+A_{2} \cdot \bar{m}_{2}+A_{3} \cdot \bar{m}_{3}}{A} \\
\operatorname{Var}\left(\bar{m}_{w}\right) & =\sum_{i=1}^{n_{j}} \frac{\left(\frac{A_{j}}{A}\right)^{2} \cdot s_{j}^{2}}{n_{j}} \\
& =\frac{\left(\frac{A_{1}}{A}\right)^{2} \cdot s_{1}^{2}}{n_{1}}+\frac{\left(\frac{A_{2}}{A}\right)^{2} \cdot s_{2}^{2}}{n_{2}}+\frac{\left(\frac{A_{3}}{A}\right)^{2} \cdot s_{3}^{2}}{n_{3}}
\end{aligned}
$$

where $A_{j}$ is the area of hydrotope unit $j$ and $A$ is the overall sampling area. The steps from (3)-(6) can be subsequently applied to any soil moisture data set categorized into hydrotopes. The level of confidence for the field average can then be calculated by solving (2) for $\bar{\chi}$.

In this paper, the sampling scheme has already been area weighed in advance; therefore, the number of samples per unit and unit area are proportional, $n_{j} \infty A_{j}$. This simplifies (5) and (6) to

$$
\begin{aligned}
\bar{m}_{w} & =\frac{1}{n} \sum_{i=1}^{n} m_{i} \\
\operatorname{Var}\left(\bar{m}_{w}\right) & =\frac{1}{n} \cdot \sum_{i=1}^{n_{j}} n_{j} \cdot s_{j}^{2}=\frac{1}{n} \cdot\left(n_{1} \cdot s_{1}^{2}+n_{2} \cdot s_{2}^{2}+n_{3} \cdot s_{3}^{2}\right) .
\end{aligned}
$$

If the variance within hydrotopes is small compared with the overall variance or, in other words, if the different hydrotope units are clearly distinct, a reduction in the overall variance can be obtained. Quantitatively, this means that when

$$
\operatorname{Var}\left(\bar{m}_{w}\right)<\operatorname{Var}\left(\bar{m}_{i}\right)=\frac{s^{2}}{n}
$$

holds, the hydrotope-based estimation of the mean will have less variance. Fig. 6 shows the improvement, given that (9) is met. High differences between the means of the chosen hydrotope units compared with the variance within each unit will yield a reduction of the overall variance, showing the advantage of a good hydrotope analysis. An improvement due to a hydrotope-based calculation of the field average and variance is given if (9) holds true. Clearly, if there are no significant differences between the hydrotopes, for example, when the landscape is completely wet or completely dry, the improvement will be minimal.

\section{Soil Moisture Data}

The data used in the following section were collected during two separate sampling campaigns. Soil moisture was determined gravimetrically by weighing and drying the samples. The center of the samples has a depth that is between 15 and $20 \mathrm{~cm}$, using soil sample rings $(\varnothing 53 \mathrm{~mm}$, height $50 \mathrm{~mm}$ ). The

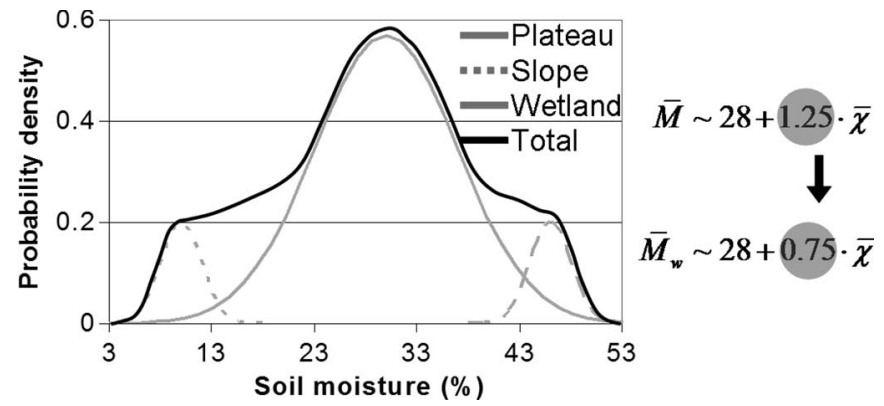

Fig. 6. Hydrotope unit separated versus regular soil moisture distribution. Probability density functions of a sample soil moisture distribution divided into (gray lines) hydrotope units and (black line) an overall soil moisture distribution are shown. The equations show a realistic example where the average soil moisture of, e.g., $28 \%$ does not change but the overall variance is reduced (e.g., 1.25 to 0.75 )

accuracy of these gravimetric measurements is within $1 \%$ of the soil moisture.

The samples were taken at the end of the wet season in 2005, which is between September 22 and October 17 (which is further denoted as campaign I), and at the onset of the wet season in 2006, which is between May 26 and June 5 (which is further denoted as campaign II). The Boudtenga study site was only sampled once during the wet season of 2005 , considering that the onset of the wet season in 2006 was very late and the location was completely dry. During the dry-season sampling (campaign II), no rain events occurred at the study sites. During the wet-season sampling (campaign I), it rained every two to three days before and in between the sampling. At a sampling depth between 15 and $20 \mathrm{~cm}$, however, the effect of rainfall during the sampling campaign is very low. Climate diagrams for rainfall and potential evaporation are shown in Fig. 2.

About 200 individual soil moisture samples (see Table II) were taken at each of the three study sites. The total (minimal) number of samples required to ensure a confidence level of $95 \%$ per study site was calculated by using existing soil moisture data for the different study sites [using (2)]. For the average soil moisture, the accuracy increases with the square root of the number of samples, which is as previously described. The Boudtenga study site is flat $(<2 \%$ slope), with inselbergs interspersed. The inselbergs consist of laterite rock and cannot be sampled for soil moisture; therefore, the Boudtenga study site only has plateau and wetland hydrotope units. The number of samples per study site was proportionally partitioned over the hydrotope units for a $10 \times 10 \mathrm{~km}$ sampling area at each study site using hydrotope maps (see Fig. 4). Within the individual hydrotope units, no sampling scheme was applied. The samples were also taken randomly in time for each campaign and study site so that any trends in soil moisture would not have resulted in different average moisture values. Soil moisture samples were collected throughout the whole day.

Considering that for satellite calibration and validation one is only interested in the sample mean, the exact type of the underlying distribution of soil moisture samples does not matter. The central limit theorem ensures that the distribution of the sample mean converges to a normal distribution. This convergence will be faster when the underlying distribution is normal or close to normal. Famiglietti et al. [33] and Choi and Jacobs [34] 
TABLE III

SHAPIRO-WILK/SHAPIRO-FRANCIA TEST FOR NORMALITY

\begin{tabular}{ccccccc}
\hline \hline & \multicolumn{2}{c}{ Boudtenga } & \multicolumn{2}{c}{ Tamale } & \multicolumn{2}{c}{ Ejura } \\
& I & II & I & II & I & II \\
\hline Plateau & $1^{1}$ & n.a & $0^{1}$ & $1^{1}$ & $0^{1}$ & $1^{1}$ \\
Wetland & $0^{\mathrm{p}}$ & n.a & $0^{1}$ & $0^{\mathrm{p}}$ & $0^{1}$ & $0^{1}$ \\
Slope & n.a & n.a & $0^{\mathrm{p}}$ & $0^{1}$ & $1^{1}$ & $0^{1}$ \\
\hline \hline
\end{tabular}

Shapiro-Wilk/-Francia test for normality per hydrotope unit, study site, and sampling campaign. 1 means non-normal and 0 normal distribution at the 0.05 significance level. The Shapiro-Wilk/-Francia test applies for sample sizes from 3 to 5000. n.a. stands for not applied.

${ }^{p}$ for platykurtic samples the Shapiro-Wilk test is applied; ${ }^{1}$ for leptokurtic samples the Shapiro-Francia test is applied.

TABLE IV

HYDROTOPE-ANALYSIS RESULTS

\begin{tabular}{|c|c|c|c|c|c|}
\hline \multirow[b]{2}{*}{ Campaign } & \multirow{2}{*}{$\begin{array}{c}\text { Boudtenga } \\
\text { I } \\
\end{array}$} & \multicolumn{2}{|c|}{ Tamale } & \multicolumn{2}{|c|}{ Ejura } \\
\hline & & $\mathrm{I}$ & II & $\mathrm{I}$ & II \\
\hline Avg_all & 0.13 & 0.17 & 0.10 & 0.16 & 0.14 \\
\hline$\sigma \_$all & 0.039 & 0.051 & 0.033 & 0.038 & 0.034 \\
\hline Avg_HT & 0.13 & 0.16 & 0.10 & 0.16 & 0.14 \\
\hline$\sigma \_\mathrm{HT}$ & 0.038 & 0.037 & 0.030 & 0.032 & 0.031 \\
\hline Samples & 197 & 187 & 204 & 200 & 200 \\
\hline
\end{tabular}

Average and standard deviation of study site soil moisture with

(Avg_HT, $\sigma \_$HT) and without (Avg_all, $\sigma \_$all) hydrotope unit separation for the two sampling campaigns ( $\mathrm{I}=$ wet conditions, $\mathrm{II}=$ dry conditions) as well as the total number of samples.

show that soil moisture samples are distributed both normally and nonnormally. Table III shows that there is also a mix of normal and nonnormal distributions. The majority of the hydrotope-unit samples are normally distributed. In turn, this gives the necessary confidence that the sample mean will indeed be normally distributed.

Satellite soil moisture products include the root-zone soil moisture, which is derived through hydrological modeling, that can readily be compared with the soil moisture that is between 15 and $20 \mathrm{~cm}$ in depth [35], [36]. These products can be arrived at through the assimilation of satellite data into soil physical models [37]. A direct comparison of the 15-20-cm soil moisture samples with the topsoil estimates from satellites is not possible. Current satellites are only capable of detecting soil moisture directly from the top $2-5 \mathrm{~cm}$ if the vegetation is not too dense. The general methodology, of course, also holds if the topsoil-moisture samples of the first $0-5 \mathrm{~cm}$ are to be used for a more direct comparison with satellite-derived soil moisture estimates.

Statistical-significance tests were performed by using a balanced one-way analysis of variance (ANOVA) and a two-sample Student's $t$-test. An omnibus Shapiro-Wilk/ Shapiro-Francia parametric hypothesis test of composite normality was performed for normality tests. For leptokurtic data, the Shapiro-Francia test is applied, and for platykurtic data, the Shapiro-Wilk test is applied. To test the performance of the hydrotope variance reduction, a Monte Carlo-based analysis is done. For each campaign, random samples corresponding to the number of samples taken in the field (see Table II) were taken from normal distributions with observed $\mu$ and $\sigma$ values from the corresponding campaign. For each randomly sampled
TABLE $\mathrm{V}$

HYDROTOPE-UNIT AVERAGES

\begin{tabular}{lccc}
\hline \hline & Plateau & Wetland & Slope \\
\hline Boudtenga_I & 0.13 & 0.15 & n.a. \\
Tamale_I & 0.14 & 0.21 & 0.18 \\
Tamale_II & $0.09^{1}$ & 0.12 & $0.08^{1}$ \\
Ejura_I & $0.15^{2}$ & $0.16^{2}$ & 0.20 \\
Ejura_II & 0.13 & 0.15 & $0.15^{3}$ \\
\hline \hline
\end{tabular}

Hydrotope unit averages per study site and sampling campaign. Superscripts indicate hydrotope units that do not show significant differences between each other (according to Student's t-test). A preliminary ANOVA analysis for each study site and campaign showed significant differences for all sampling sets. n.a. stands for not applied.

TABLE VI

RANDOM ALTERNATIVE TEST

\begin{tabular}{lccccc}
\hline \hline & Boudtenga & \multicolumn{2}{c}{ Tamale } & \multicolumn{2}{c}{ Ejura } \\
Campaign & I & I & II & I & II \\
\hline mu & 0.13 & 0.17 & 0.10 & 0.16 & 0.14 \\
sigma & 0.039 & 0.051 & 0.033 & 0.038 & 0.034 \\
Random alternative & 0.65 & 1.00 & 0.94 & 1.00 & 0.95 \\
Samples & 197 & 187 & 204 & 200 & 200 \\
\hline \hline
\end{tabular}

Results of a Monte Carlo analysis of the variance reduction gained through hydrotope analysis. For each campaign random samples, corresponding to the number of samples taken in the field, were taken from normal distributions with observed mu and sigma values. For each randomly sampled set (10000 for each campaign) the standard deviation was calculated. Random alternative is one minus the chance that a random sampling campaign would give a lower overall standard deviation than the hydrotope derived standard deviation.

set (10000 for each campaign), the standard deviation was calculated. Based on the distribution of the randomly sampled standard deviations, one minus the chance that a random sample would yield a lower variance than the hydrotope method is calculated.

\section{RESUlts AND ANALYSis}

The effectiveness of a hydrotope-unit-based analysis is described via the reduction in overall variance and the minimization of bias in the sample. To measure the effect of the hydrotope analysis, the calculation of overall averages, standard deviation, and variance is performed according to the hydrotope-unit separation [see (7) and (8)] and by calculating the same variables over the whole sampling volume without using any hydrotope-unit separation [see (2)].

An effective bias minimization for our study sites cannot be shown directly without additional independent data. Indirectly, significant differences in hydrotope-unit averages suggest that biased sampling would result in wrong field averages.

Table IV shows the results of the calculations. Overall, the variance has been reduced by using hydrotope-unit separation in the calculation of the field standard deviations. Due to the area-weighed sampling, differences in field averages and between regular and hydrotope-weighed averaging cannot be seen. A one-way ANOVA for average soil moisture of all the 

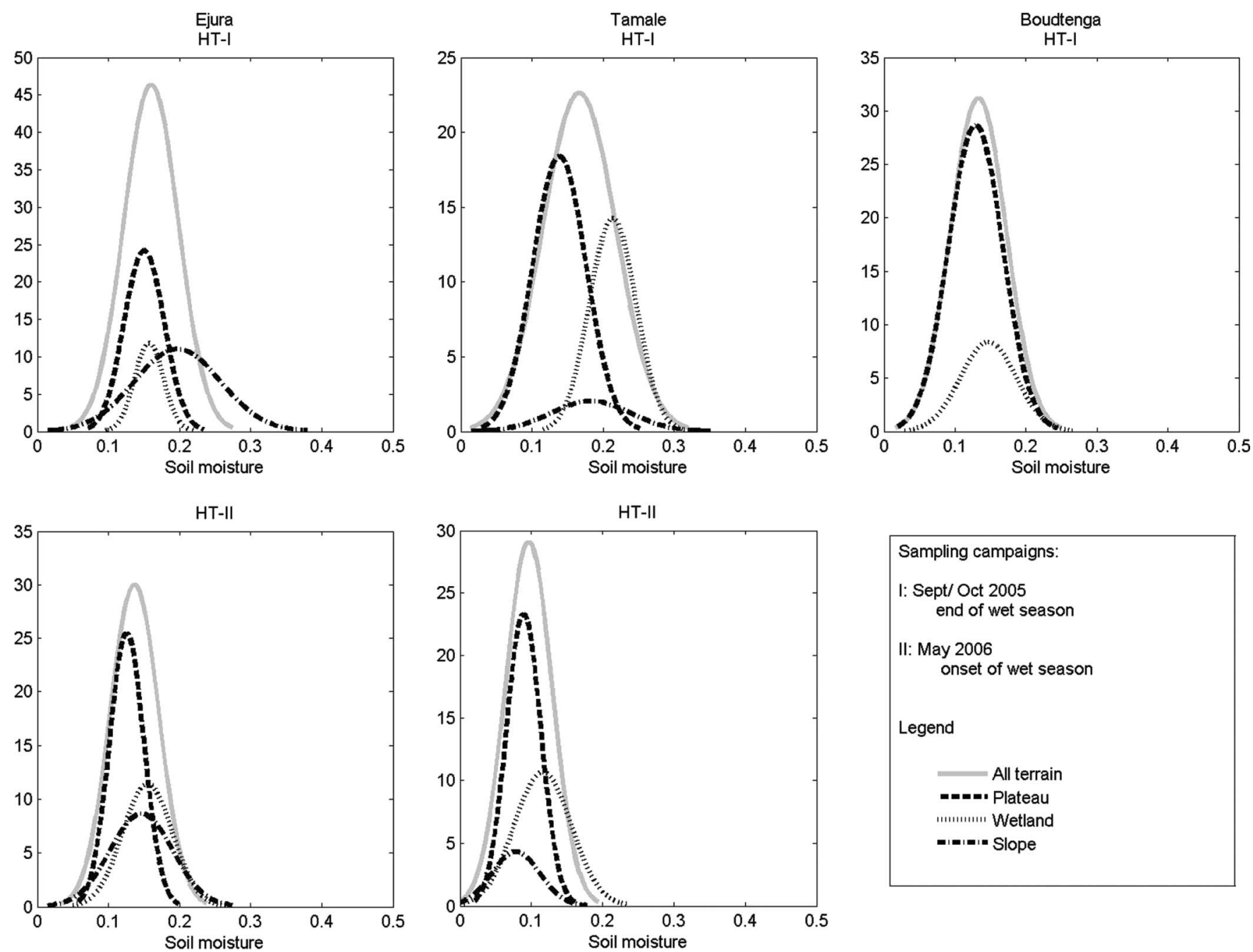

Fig. 7. Histograms of overall and hydrotope sample distributions. The histogram sets are organized by study site (Ejura, Tamale, and Boudtenga) and sampling campaign (I and II). Gray lines depict the overall sample distribution, and dotted lines depict the sample distributions of the individual hydrotope units.

three campaigns and study sites showed significant differences between all hydrotope units. A subsequent Student's $t$-test for significant differences in between the different hydrotope units also showed significant differences for most hydrotope units (see Table V).

To show how the hydrotope reduction in the overall variance performs against the overall variance from random sampling, a Monte Carlo analysis was done. Table VI shows that even in cases where the variance reduction is negligible, the chance that the hydrotope method yields superior results is high $(>65 \%)$.

Different reductions in the overall variance highlight regional and seasonal distinctions between study sites and sampling times that can be best visualized via the histograms of the different hydrotope units (see Fig. 7). The seasonality and overall moisture conditions at the three locations are the two major causes that determine the level of variance reduction and the differentiability between the hydrotope units.

Ejura, which is the location with most rainfall, generally shows a high moisture level throughout both seasons. Slight differences can be seen between the three hydrotope units and the two seasons. During the wet season, the plateau and wetland areas are similar (see Fig. 7), whereas the slope unit shows a slight offset. The shallow soils in the slope unit lead to lateral flow just above the bedrock layer that results in a higher moisture content of the shallow soils, which can be seen from the data (see Table V and Fig. 7). Differences between the hydrotope units can be seen and are as expected. Due to the overall high moisture content, however, the units show uniform behavior which dampens the distinction between different units.

Tamale, being a more moisture-limited location than Ejura, shows a good distinction between plateau and wetland units during the wet season. Fig. 7 shows the clear differentiation between the two units, which is also reflected in the highest variance reduction (see Table IV). In the dry season, a more uniform picture emerges. This moisture-limited location has ephemeral streams and is very dry. The overall dryness minimizes the differences between hydrotope units. Therefore, the dry-season sampling only shows slight differences between the plateau and wetland units.

Boudtenga, which is the northernmost study site, shows a uniform soil moisture distribution. Although the plateau and wetland units show significantly different unit averages, similar unit variances result in low overall variance reduction.

All study sites correspond well with respect to the governing effect of overall wetness (and dryness) on hydrotope distinction. Comparing the Ejura results with the Tamale 
dry- and wet-season samplings, it is shown that unit differences are reduced under extremely wet and dry conditions. This suggests a homogenization of soil moisture throughout all study sites under extremely dry and extremely wet conditions. Intermediate conditions, such as during the Tamale campaign-I sampling, show a clear reduction in the overall variance.

\section{CONCLUSION AND Discussion}

The main focus of the presented methodology is to derive statistically stable soil moisture field averages for satellite validation. Results show that the overall variance reduction is seasonally and spatially dependent. Significant differences in average soil moisture between the majority of the hydrotope units also suggest bias minimization.

The different levels of variance reduction highlight the spatial and temporal differences between the study sites and sampling times. The low reduction levels in the overall variance at some study sites can be due to improper hydrotope-unit identification or due to inhomogeneous soil moisture patterns. In our case, improper hydrotope-unit definition is unlikely, considering that most hydrotope units show significant differences between each other (see Table V).

Moisture patterns shift over time in accordance with moisture availability. Western et al. [11] presented results that show high levels of soil moisture organization during wet Australian winter conditions and random variability during dry summer conditions. In our case, results confirm this soil moisture uniformity for dry conditions (e.g., Boudtenga campaign I) and further suggest a similar behavior under extremely wet conditions (e.g., Ejura campaign I). Under intermediate West African conditions, high levels of soil moisture organization between given hydrotope units are supported (Tamale campaign I). The overall level and range of soil moisture values in our study vary between 0.10 and 0.17 , which is a rather narrow range of values compared with other studies [11], [33]. In different climates that show higher soil moisture ranges, the hydrotope analysis can be expected to result in higher variance reduction. A definitive answer toward the quality of our hydrotope-unit identification cannot be given. Previous studies, however, support the conclusion that under dry conditions, soil moisture patterns become more homogenous, which can be confirmed by the presented results and can be extended to extremely wet conditions as well.

This paper confirms that well-defined hydrotope units yield improved pixel-scale field averages. The hydrotope definitions for the Volta Basin were based on the simplification of the catena approach by Park and van de Giesen [22]. The simplification was based on qualitative insight into the main hydrological processes that are relevant in this basin. Without prior hydrological knowledge, one should, in the first instance, maintain a larger number of hydrotopes based on the landscape position. This will minimize the chance of bias in the sampling scheme and, subsequently, result in a low variance of the estimate of the mean soil moisture content.

\section{ACKNOWLEDGMENT}

The authors would like to thank the GLOWA Volta Project, particularly the offices in Ghana and Burkina Faso, for their extensive support during the field campaigns and also the reviewers for their helpful and clarifying comments.

\section{REFERENCES}

[1] Y. H. Kerr, P. Waldteufel, J. P. Wigneron, J. M. Martinuzzi, J. Font, and M. Berger, "Soil moisture retrieval from space: The Soil Moisture and Ocean Salinity (SMOS) mission," IEEE Trans. Geosci. Remote Sens., vol. 39, no. 8, pp. 1729-1735, Aug. 2001.

[2] D. Entekhabi, E. G. Njoku, P. Houser, M. Spencer, T. Doiron, Y. J. Kim, J. Smith, R. Girard, S. Belair, W. Crow, T. J. Jackson, Y. H. Kerr, J. S. Kimball, R. Koster, K. C. McDonald, P. E. O'Neill, T. Pultz, S. W. Running, J. C. Shi, E. Wood, and J. van Zyl, "The Hydrosphere State (Hydros) satellite mission: An Earth system pathfinder for global mapping of soil moisture and land freeze/thaw," IEEE Trans. Geosci. Remote Sens., vol. 42, no. 10, pp. 2184-2195, Oct. 2004.

[3] E. G. Njoku, T. J. Jackson, V. Lakshmi, T. K. Chan, and S. V. Nghiem, "Soil moisture retrieval from AMSR-E," IEEE Trans. Geosci. Remote Sens., vol. 41, no. 2, pp. 215-229, Feb. 2003.

[4] W. T. Crow, S. T. K. Chan, D. Entekhabi, P. R. Houser, A. Y. Hsu, T. J. Jackson, E. G. Njoku, P. E. O’Neill, J. C. Shi, and X. W. Zhan, “An observing system simulation experiment for Hydros radiometer-only soil moisture products," IEEE Trans. Geosci. Remote Sens., vol. 43, no. 6 , pp. 1289-1303, Jun. 2005.

[5] J. Cashion, V. Lakshmi, D. Bosch, and T. J. Jackson, "Microwave remote sensing of soil moisture: Evaluation of the TRMM Microwave Imager (TMI) satellite for the Little River Watershed Tifton, Georgia," J. Hydrol., vol. 307, no. 1-4, pp. 242-253, Jun. 9, 2005.

[6] K. De Ridder, "Surface soil moisture monitoring over Europe using Special Sensor Microwave/Imager (SSM/I) imagery," J. Geophys. Res.-Atmos., vol. 108, no. D14, p. 4422, Jul. 26, 2003.

[7] C. Prigent, F. Aires, W. B. Rossow, and A. Robock, "Sensitivity of satellite microwave and infrared observations to soil moisture at a global scale: Relationship of satellite observations to in situ soil moisture measurements," J. Geophys. Res.-Atmos., vol. 110, no. D7, p. D07 110, Apr. 13, 2005.

[8] W. Wagner, G. Lemoine, and H. Rott, "A method for estimating soil moisture from ERS scatterometer and soil data," Remote Sens. Environ. vol. 70, no. 2, pp. 191-207, Nov. 1999.

[9] G. Vachaud, A. P. Desilans, P. Balabanis, and M. Vauclin, "Temporal stability of spatially measured soil-water probability density-function," Soil Sci. Soc. Amer. J., vol. 49, no. 4, pp. 822-828, Jul. 1985.

[10] R. G. Kachanoski and E. de Jong, "Scale dependence and the temporal persistence of spatial patterns of soil-water storage," Water Resour. Res., vol. 24, no. 1, pp. 85-91, Jan. 1988.

[11] A. W. Western, G. Bloschl, and R. B. Grayson, "Geostatistical characterisation of soil moisture patterns in the Tarrawarra catchment," J. Hydrol., vol. 205, no. 1/2, pp. 20-37, Feb. 26, 1998.

[12] D. D. Bosch, V. Lakshmi, T. J. Jackson, M. Choi, and J. M. Jacobs, "Large scale measurements of soil moisture for validation of remotely sensed data: Georgia soil moisture experiment of 2003," J. Hydrol., vol. 323, no. 1-4, pp. 120-137, May 30, 2006.

[13] J. M. Jacobs, B. P. Mohanty, E. C. Hsu, and D. Miller, "SMEX02: Field scale variability, time stability and similarity of soil moisture," Remote Sens. Environ., vol. 92, no. 4, pp. 436-446, Sep. 30, 2004.

[14] B. P. Mohanty and T. H. Skaggs, "Spatio-temporal evolution and timestable characteristics of soil moisture within remote sensing footprints with varying soil, slope, and vegetation," Adv. Water Resour., vol. 24, no. 9/10, pp. 1051-1067, Nov./Dec. 2001.

[15] G. Matheron, "Principles of geostatistics," Econ. Geol., vol. 58, no. 8, pp. 1246-1266, Dec. 1963

[16] A. Bardossy and W. Lehmann, "Spatial distribution of soil moisture in a small catchment. Part 1: Geostatistical analysis," J. Hydrol., vol. 206, no. 1, pp. 1-15, Apr. 1998.

[17] H. Laurent, I. Jobard, and A. Toma, "Validation of satellite and groundbased estimates of precipitation over the Sahel," Atmos. Res., vol. 48, pp. 651-670, Jun. 1998.

[18] A. W. Western and R. B. Grayson, "The Tarrawarra data set: Soil moisture patterns, soil characteristics, and hydrological flux measurements," Water Resour. Res., vol. 34, no. 10, pp. 2765-2768, Oct. 1998.

[19] A. Robock, K. Y. Vinnikov, G. Srinivasan, J. K. Entin, S. E. Hollinger, N. A. Speranskaya, S. X. Liu, and A. Namkhai, "The global soil moisture data bank," Bull. Amer. Meteorol. Soc., vol. 81, no. 6, pp. 1281-1299, Jun. 2000.

[20] W. A. Flügel, "Combining GIS with regional hydrological modelling using hydrological response units (HRUs): An application from Germany," Math. Comput. Simul., vol. 43, no. 3-6, pp. 297-304, Mar. 1997. 
[21] S. J. Park, K. McSweeney, and B. Lowery, "Identification of the spatial distribution of soils using a process-based terrain characterization," Geoderma, vol. 103, no. 3/4, pp. 249-272, Oct. 2001.

[22] S. J. Park and N. van de Giesen, "Soil-landscape delineation to define spatial sampling domains for hillslope hydrology," J. Hydrol., vol. 295, no. $1-4$, pp. $28-46$, Aug. 2004.

[23] N. van de Giesen, H. Kunstmann, G. Jung, J. Liebe, M. Andreini, and P. L. G. Vlek, "The GLOWA Volta project: Integrated assessment of feedback mechanisms between climate, landuse, and hydrology," in Climatic Change. Implications for the Hydrological Cycle and for Water Management, M. Beniston, Ed. Norwell, MA: Kluwer, 2002, pp. 151-170.

[24] P. N. Windmeijer and W. Andriesse, Inland Valleys in West Africa: An Agro-Ecological Characterization of Rice-Growing Environments, vol. 52. Wageningen, The Netherlands: ILRI Publication, 1983

[25] "FAOCLIM 2: World-Wide Agroclimatic Database," Environment and Natural Resources Working Paper Number 5, Food Agriculture Org. United Nations (FAO), Rome, Italy, 2001. Version 2.01.

[26] J. Friesen, M. Andreini, W. Andah, B. Amisigo, and N. van de Giesen, Storage Capacity and Long-Term Water Balance of the Volta Basin, West Africa. Wallingford, U.K.: IAHS-AISH Publication, 2005.

[27] M. C. Masiyandima, N. van de Giesen, S. Diatta, P. N. Windmeijer, and T. M. Steenhuis, "The hydrology of inland valleys in the sub-humid zone of West Africa: Runoff processes in the M'be experimental watershed," Hydrol. Process., vol. 17, no. 6, pp. 1213-1225, 2003.

[28] T. J. Stomph, N. de Ridder, T. S. Steenhuis, and N. C. van de Giesen, "Scale effects of Hortonian overland flow and rainfall-runoff dynamics: Laboratory validation of a process-based model," Earth Surf. Processes Landf., vol. 27, no. 8, pp. 847-855, Aug. 2002.

[29] N. C. van de Giesen, T. J. Stomph, and N. de Ridder, "Scale effects of Hortonian overland flow and rainfall-runoff dynamics in a West African catena landscape," Hydrol. Process., vol. 14, no. 1, pp. 165175, Jan. 2000.

[30] E. Rodriguez, C. S. Morris, J. E. Belz, E. C. Chapin, J. M. Martin, and W. Daffer, "An assessment of the SRTM topographic products," in Jet Propulsion Lab., Pasadena, CA, Tech. Rep. JPL D-31639, 2005.

[31] T. M. Lillesand and R. W. Kiefer, Remote Sensing and Image Interpretation. New York: Wiley, 1994.

[32] J. R. Eastman, IDRISI Kilimanjaro: Guide to GIS and Image Processing. Worcester, MA: Clark Labs, 2003.

[33] J. S. Famiglietti, J. A. Devereaux, C. A. Laymon, T. Tsegaye, P. R. Houser, T. J. Jackson, S. T. Graham, M. Rodell, and P. J. van Oevelen, "Groundbased investigation of soil moisture variability within remote sensing footprints during the Southern Great Plains 1997 (SGP97) hydrology experiment," Water Resour. Res., vol. 35, no. 6, pp. 1839-1851, Jun. 1999.

[34] M. Choi and J. M. Jacobs, "Soil moisture variability of root zone profiles within SMEX02 remote sensing footprints," Adv. Water Resour., vol. 30, no. 4, pp. 883-896, Apr. 2007.

[35] M. Owe, R. A. M. de Jeu, and T. H. R. Holmes, "Multisensor historical climatology of satellite-derived global land surface soil moisture," J. Geophys. Res._Earth Surface, vol. 113, no. F1, p. F01 002, 2008.

[36] W. Wagner and K. Scipal, "Large-scale soil moisture mapping in Western Africa using the ERS scatterometer," IEEE Trans. Geosci. Remote Sens., vol. 38, no. 4, pp. 1777-1782, Jul. 2000.

[37] S. C. Dunne, D. Entekhabi, and E. G. Njoku, "Impact of multiresolution active and passive microwave measurements on soil moisture estimation using the ensemble Kalman smoother," IEEE Trans. Geosci. Remote Sens., vol. 45, no. 4, pp. 1016-1028, Apr. 2007.

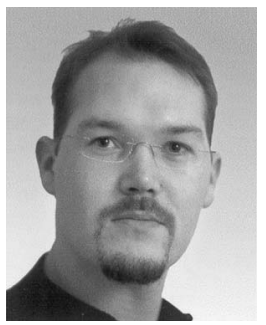

Jan Friesen received the Diploma M.Sc. degree in geography from the University of Bonn, Bonn, Germany, in 2002. He is currently working toward the Ph.D. degree in the Water Resources Section, Faculty of Civil Engineering and Geosciences, Delft University of Technology, Delft, The Netherlands.

His research interests include remote sensing, hydrology, vegetation water studies, and the effect of vegetation water on remotely sensed soil moisture estimates.

Mr. Friesen is a member of the International Association of Hydrological Sciences and of the European Geophysical Union.
Charles Rodgers received the B.A. degree in economics from the University of Wisconsin, Madison, in 1984, the M.Sc. degree in agricultural and applied economics from the University of Minnesota, St. Paul, in 1989, and the $\mathrm{Ph} . \mathrm{D}$. degree in civil and environmental engineering from the University of Wisconsin, in 1997.

After a postdoctoral position with the International Food Policy Research Institute, Washington, DC, he was with the Center for Development Research, University of Bonn, Bonn, Germany, where, for two years, he was a Senior Researcher and where he was the Scientific Coordinator of the Global Change in the Hydrological Cycle Volta Project. He is currently a consultant based in Washington, DC.

Dr. Rodgers is a member of the International Association of Agricultural Economists and of the American Geophysical Union.

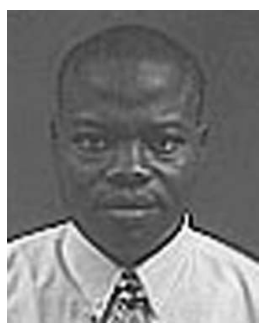

Philip G. Oguntunde received the Ph.D. degree in water resources engineering from the Center for Development Research, University of Bonn, Bonn, Germany, in 2004.

$\mathrm{He}$ is currently with the Department of Agricultural Engineering, School of Engineering, Federal University of Technology, Akure, Nigeria, where he holds a lectureship position. His research interests include hydrology, ecohydrology, water management, hydrological impacts of land use/cover and climate change, modeling of hydrological processes, and agrometeorology.

Dr. Oguntunde is a registered engineer with the Council for the Registration of Engineering in Nigeria, a member of the Nigerian Society of Engineers, of the American Society of Civil Engineers, and of the International Association of Hydrological Sciences.

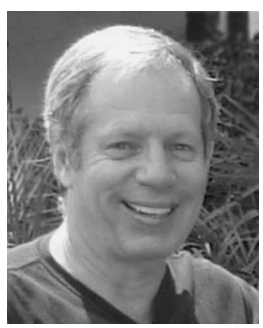

Jan M. H. Hendrickx received the M.S. degree in civil engineering and irrigation from Wageningen Agricultural University, Wageningen, The Netherlands, in 1975 and the Ph.D. degree in soil physics from New Mexico State University, Las Cruces, in 1984.

Since 1990, he has been a Professor of Hydrology with the Department of Earth and Environmental Science, New Mexico Institute of Mining and Technology, Socorro. His current research interests are hydrology remote sensing by using optical imagery for the determination of evapotranspiration and soil moisture, the effects of soil conditions on the detection of improvised explosive devices using radar and thermal sensors, and soil hydrological processes.

Dr. Hendrickx is a Fellow of the American Soil Science Society and of the Fulbright program.

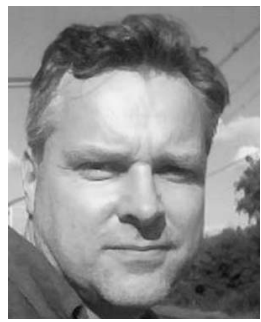

Nick van de Giesen received the Kandidaats B.S degree and the M.Sc. degree in land and water management from Wageningen Agricultural University, Wageningen, The Netherlands, in 1984 and 1987, respectively, and the Ph.D. degree in agricultural and biological engineering from Cornell University, Ithaca, NY, in 1994.

After a postdoctoral position with the West Africa Rice Development Association, Bouaké, Côte d'Ivoire, he was a Senior Researcher for six years with the Center for Development Research (ZEF), University of Bonn, Bonn, Germany, where he was the Scientific Coordinator of the Global Change in the Hydrological Cycle Volta Project. Since 2004, he has been with the Water Resources Section, Faculty of Civil Engineering and Geosciences, Delft University of Technology, Delft, The Netherlands, where he is currently the "van Kuffeler" Chair of Water Resources Management.

Dr. van de Giesen is the Secretary of the International Commission on Water Resources Systems of the International Association of Hydrological Sciences, the Chairman of the Committee on Water Policy and Management of the European Geosciences Union, the Chairman of the Netherlands Commission on Irrigation and Drainage, and a Senior Fellow with the ZEF, University of Bonn. 